\title{
Cryptosporidium parvum biliary tract infection in adult immunocompetent and immunosuppressed mice
}

\author{
R. VERDON*†, JULIETTE POLIANSKI* $\dagger$, A GRODET $\ddagger$ L. GARRY† and C. CARBON† \\ * Service de Réanimation Médicale et Maladies Infectieuses, CHU Côte de Nacre, 14033 Caen Cedex, †Institut \\ National de la Recherche Scientifique et Médicale Unité 13 and \$Institut National de la Recherche Scientifique \\ et Médicale Unité 82, CHU Bichat-Claude-Bernard, 46 Rue Henri-Huchard, 75877 Paris Cedex, France
}

\begin{abstract}
Biliary tract infection by Cryptosporidium parvum is a frequent complication of intestinal cryptosporidiosis in immunosuppressed patients. Although biliary tract infection can be produced in immunosuppressed models as a late complication of intestinal infection, there is no infection model in immunocompetent animals. A murine model of biliary tract cryptosporidiosis was developed by direct intra-gall bladder injection of $C$. parvum oocysts. In adult immunocompetent mice, intracellular parasitic stages were detected in the epithelium of the common bile duct in all animals on day 7 post-inoculation (p.i.). These findings were associated with a strong inflammatory reaction. Infection was cleared between days 14 and 21 p.i. All animals developed significant levels of specific serum and bile IgG, IgA and IgM. Dexamethasone treatment resulted in the inability of animals to eradicate the parasite and the establishment of ileal parasitism. This model can be used to study the immunological mechanisms imvolved in the control of biliary cryptosporidiosis.
\end{abstract}

\section{Introduction}

The protozoan Cryptosporidium parvum is a cause of opportunist chronic enteric infection in immunosuppressed patients, particularly in those with the acquired immune deficiency syndrome (AIDS) [1]. Extraintestinal infections have been described in immunosuppressed patients, including parasite development on respiratory and biliary epithelial surfaces [1]. The most frequent extra-intestinal infection site is the biliary tract, resulting in cholecystitis or cholangitis [1].

C. parvum is identified in the bile or in the intestine of $20-65 \%$ of patients with the so-called AIDS-associated cholangiopathy [2-4]. The development of biliary tract infection has a severe clinical impact on the course of intestinal cryptosporidiosis. Recent data suggest that the presence of biliary tract cryptosporidiosis is associated with a poor prognosis in AIDS patients [5]. Moreover, the presence of a biliary reservoir of infection may be responsible for the chronicity of infection as well as the failure to eradicate the parasite by chemotherapy or immunotherapy.

Biliary tract infection has been described only in

Received 13 March 1997; accepted 18 May 1997.

Corresponding author: Dr R. Verdon. immunosuppressed animal models of cryptosporidiosis, such as nude or CD4 depleted mice, corticosteroidtreated rats and SCID mice [6-11]. In these models, biliary tract infection was not established in most cases before 4-5 weeks after intestinal oocyst challenge. Because there is no model of biliary cryptosporidiosis in immunocompetent animals, the immunological mechanisms involved in the control of biliary tract infection are unknown.

The aim of this study was to develop a model of biliary cryptosporidiosis in immunocompetent small laboratory animals in order to study inflammatory and immunological processes. In this model adult immunocompetent mice developed a spontaneously resolving biliary tract cryptosporidiosis after direct inoculation of $C$. parvum oocysts into the gall bladder. Biliary tract infection in this model is accompanied by severe inflammatory changes and serum and bile antibody responses and can be modulated by immunosuppressive treatments such as corticosteroids.

\section{Materials and methods}

\section{Parasite}

C. parvum oocysts (given by Dr M. Naciri, Institut National de la Recherche Agronomique, Tours, France) 
were propagated in calves inoculated with oocysts isolated from an infected child. Oocysts were purified from calf faeces by flotation in saturated $\mathrm{NaCl}$ solution and disinfected with commercial bleach at a final concentration of sodium hypochlorite $0.25 \%$ [12]. Disinfected oocysts were rinsed four times in sterile phosphate-buffered saline (PBS) to remove the hypochlorite.

\section{Animals and experimental design}

$\mathrm{BALB} / \mathrm{c}$ and $\mathrm{C} 57 \mathrm{BL} / 6$ mice were purchased from Iffa Credo (France) and used between 6 and 8 weeks of age.

Experiment 1. Eight BALB/c mice were infected by the injection of $10^{6}$ oocysts into the gall bladder by a standardised technique (see below) and killed on day 7 (four animals) and 11 (four animals) post-inoculation (p.i.) for histological study of the gall bladder and common bile duct. At both time-points, samples of one inoculated animal were also processed for transmission electron microscopy. As control, eight BALB/c mice were inoculated with PBS alone (two mice), with heatinactivated oocysts (two), with a filtrate of the oocyst suspension passed through a $0.22-\mu \mathrm{m}$ filter (two) or underwent a needle puncture without injection (two); one of each control group was killed on days 7 and 11.

Experiment 2. To assess the kinetics of common bile duct infection, 30 adult BALB/c mice were inoculated in the gall bladder with $10^{6}$ oocysts. On days $7,14,21$, 28 and 35 p.i., five randomly-assigned mice were killed and histological sections of the common bile duct were examined for infection. Another six mice were inoculated with PBS and used as negative controls one animal being killed on the same days as the experimental animals. In parallel to this experiment, six $\mathrm{BALB} / \mathrm{c}$ mice were inoculated in the gall bladder with $10^{6}$ oocysts and their serum sampled on days $0,7,14$, 21, 28 and 35 p.i. Two $\mathrm{BALB} / \mathrm{c}$ mice that were inoculated with PBS alone were used as negative controls. These eight mice were killed on day 35 for histological study of their common bile duct and for collection of gall bladder bile. The gall bladder was put in a microfuge tube, opened, immersed in $30 \mu \mathrm{l}$ of PBS-BSA $1 \%$ and frozen at $-20^{\circ} \mathrm{C}$ until use. Serum and gall bladder bile samples were used for assessment of antibody response against $C$. parvum (see below).

Experiment 3. To evaluate the possibility of strain differences, $16 \mathrm{BALB} / \mathrm{c}$ and $16 \mathrm{C} 57 \mathrm{BL} / 6$ mice were infected with $10^{6}$ oocysts by injection into the gall bladder. Groups of four animals of each strain were randomly assigned to be killed on days 3, 7, 10 and 14 p.i. for histological study of common bile duct, duodenum and ileum. On each day one mouse of each strain that had been inoculated with PBS alone was killed as control.
Experiment 4. To evaluate the effect of immunosuppression on the course of the disease, $12 \mathrm{BALB} / \mathrm{c}$ and $12 \mathrm{C} 57 \mathrm{BL} / 6$ mice were immunosuppressed throughout the experiment by the addition of dexamethasone to the drinking water from 7 days before inoculation. They were inoculated with $10^{6}$ oocysts in the gall bladder on the same day as animals of experiment 3 and both experiments were run in parallel. Groups of four animals of each strain and one control animal inoculated with PBS were randomly assigned to be killed on days 7,14 and 21 p.i. for histological study of the common bile duct, duodenum and ileum.

This study was done in accordance with current regulations regarding the care and use of laboratory animals in the European Communities (Journal Officiel des Communautés Européennes, 18 Décembre 1986, L358).

\section{Surgical and histological procedures}

After fasting for $12 \mathrm{~h}$, animals were anaesthetised with pentobarbital and were given antibiotic prophylaxis with amoxicillin-clavulanic acid (Augmentin ${ }^{\mathrm{R}}$ ) $125 \mathrm{mg} / \mathrm{kg}$ subcutaneously. After a laparotomy incision of $1 \mathrm{~cm}$ had been made, oocysts suspended in a total volume of $25 \mu \mathrm{l}$ of sterile PBS were injected into the gall bladder with a 33-gauge needle and the abdominal wall was sutured. The total procedure took $15 \mathrm{~min} /$ animal.

Animals were killed with pentobarbital. After laparotomy, the whole biliary tract and liver, and $1 \mathrm{~cm}$ of duodenum and ileum wre removed and fixed in formalin $10 \%$. All histological specimens were stained with haematoxylin-eosin. For assessment of infection, a semi-quantitative score was used: 0 , no detectable parasites; $1,1-30 \%$ of the epithelium parasitised; 2 , $31-60 \%$ of the epithelium parasitised; $3,>60 \%$ of the epithelium parasitised. Sections of the common bile duct were fixed in glutaraldehyde, prepared for and examined by transmission electron microscopy by routine techniques.

\section{Serology}

Immunoglobulin titres were determined by ELISA with the same $C$. parvum isolate for antigen as for inoculation. Oocysts were purified as described above, resuspended in PBS and disrupted by 15 cycles of thawing and freezing. Microtitration plates (Nunc Laboratories) were coated with $5 \times 10^{5}$ disrupted oocysts in $50 \mu \mathrm{l} /$ well. After incubation at $4^{\circ} \mathrm{C}$ overnight, plates were washed free of unbound antigen and incubated with PBS-BSA $1 \%$ for $1 \mathrm{~h}$ at $37^{\circ} \mathrm{C}$. After the plates had been washed three times with PBS, $50 \mu 1$ of test sample in PBS-BSA $1 \%$ ( 1 in 50 and 1 in 200 dilutions of serum and bile preparation, respectively) were added per well in triplicate and incubated for $1 \mathrm{~h}$ at $37^{\circ} \mathrm{C}$. After further washing three times with PBS 
containing Tween $200.05 \%, 50 \mu 1$ of alkaline phosphatase-conjugated goat anti-mouse IgG, IgA or IgM (Sigma) diluted in PBS-BSA $1 \%(1$ in 20000,1 in 40000 and 1 in 70000 , respectively) were added per well and incubated for $1 \mathrm{~h}$ at $37^{\circ} \mathrm{C}$. Plates were washed five times with PBS containing Tween $200.05 \%$ and $50 \mu 1$ of $p$-nitrophenyl phosphate (Sigma) $1 \mathrm{mg} / \mathrm{ml}$ in buffer (100 mM Tris-HCl, pH 9.5, $100 \mathrm{mM} \mathrm{NaCl}, 5 \mathrm{mM}$ $\mathrm{MgCl}_{2}$ ) were added to each well and allowed to react at room temperature. The hydrolysis of substrate was quantified by measuring the optical density (OD) at $405 \mathrm{~nm}$ with a microplate ELISA reader. For interpretation of results, the mean and SD of OD readings for the negative controls were calculated. Results were expressed as the difference between the mean OD reading from a test sample run in triplicate minus the mean OD reading plus 2 SD of the negative controls. A specimen was considered positive if the mean OD from triplicate wells was greater than the mean plus $2 \mathrm{SD}$ of the negative control.

\section{Statistics}

Results are presented as mean and SEM. Comparison of means was performed by the Mann-Whitney test. All results presented have been confirmed in at least two experiments.

\section{Results}

The inoculation of oocysts into the gall bladder was well tolerated in all experiments with no mortality related to this procedure. In experiment 1 , all adult mice that were inoculated with oocysts had macroscopic inflammatory lesions of the gall bladder and the common bile duct on days 7 and 11 p.i., including dilatation of the lumen with thickening of the wall of the common bile duct, and thickening and retraction of the gall bladder (Fig. 1A). Adhesions of the gall bladder wall to the adjacent hepatic lobe were observed. In contrast, controls that were inoculated with PBS, heat-inactivated oocysts, the filtration product of oocyst preparation or that received a simple puncture without injection did not show any macroscopic alterations (Fig. 1B). Histological examination on days 7 and 11 p.i. revealed the presence of $C$. parvum developmental stages on the gall bladder and common bile duct epithelial surfaces (Fig. 2A and B). Marked histological abnormalities included thickening of the common bile duct wall and infiltration with polymorphonuclear cells, lymphocytes and monocytes. Alteration of the epithelial structure was frequently observed, including pseudo-stratification and cuboid cells. No parasitic infection was observed in controls and histological changes were minimal or absent (Fig. 2C).

Infection of biliary epithelial cells by $C$. parvum was verified by transmission electron microscopy of common bile duct samples on days 7 and 11 p.i. in two adult immunocompetent BALB/c mice (Fig. 3). Examination of sections demonstrated the development of parasitic stages within biliary epithelial cells. Specific features of $C$. parvum parasitism were observed, including fusion of the parasite and host cell membranes and development of the intracellular stages within a parasitophorous vacuole in an extracytoplasmic intracellular location.
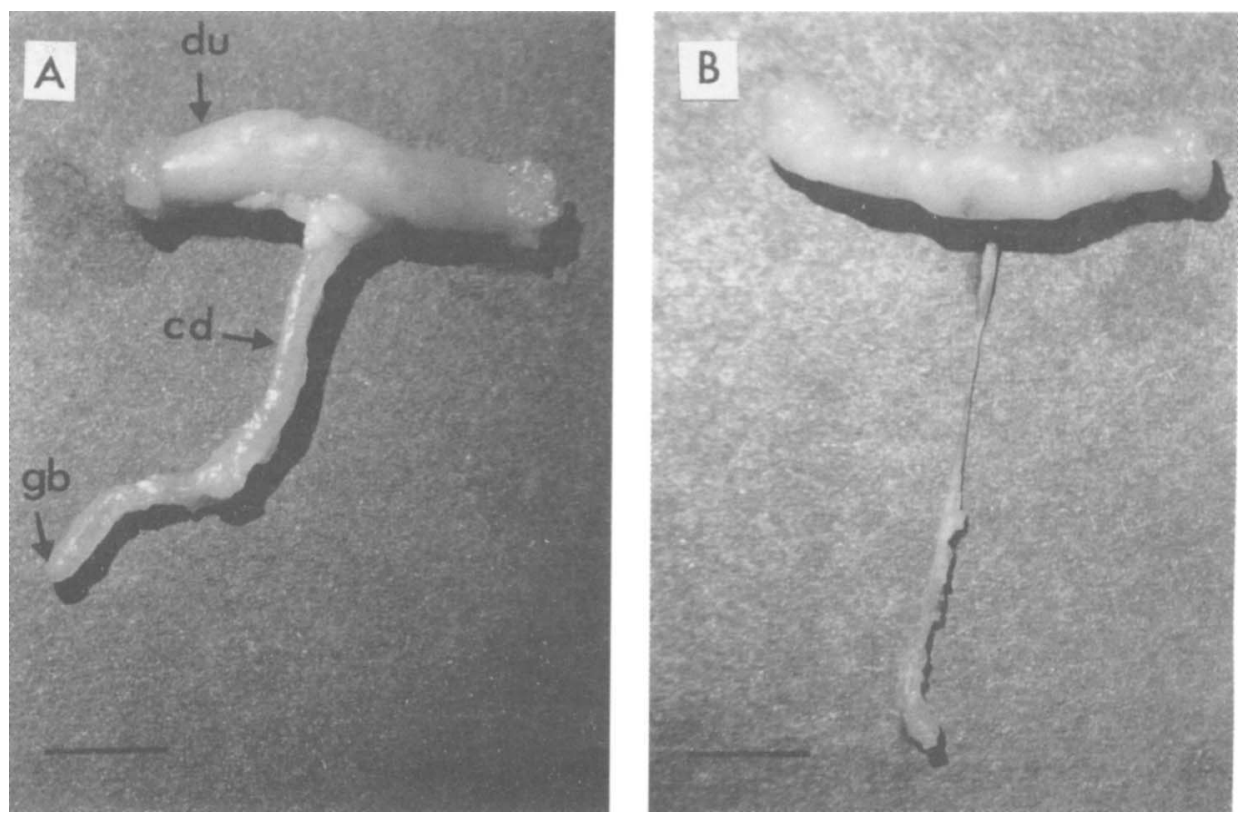

Fig. 1. (A) Cholangitis in an immunocompetent adult BALB/c mouse 7 days after the inoculation of $10^{6}$ C. parvum oocysts into the gall bladder (gb). The common bile duct (cd) is dilated and its wall thickened. The duodenum (du) is normal. (B) No gross inflammatory changes were detected in a control of the same age and strain inoculated with PBS. $\mathrm{Bar}=5 \mathrm{~mm}$. 

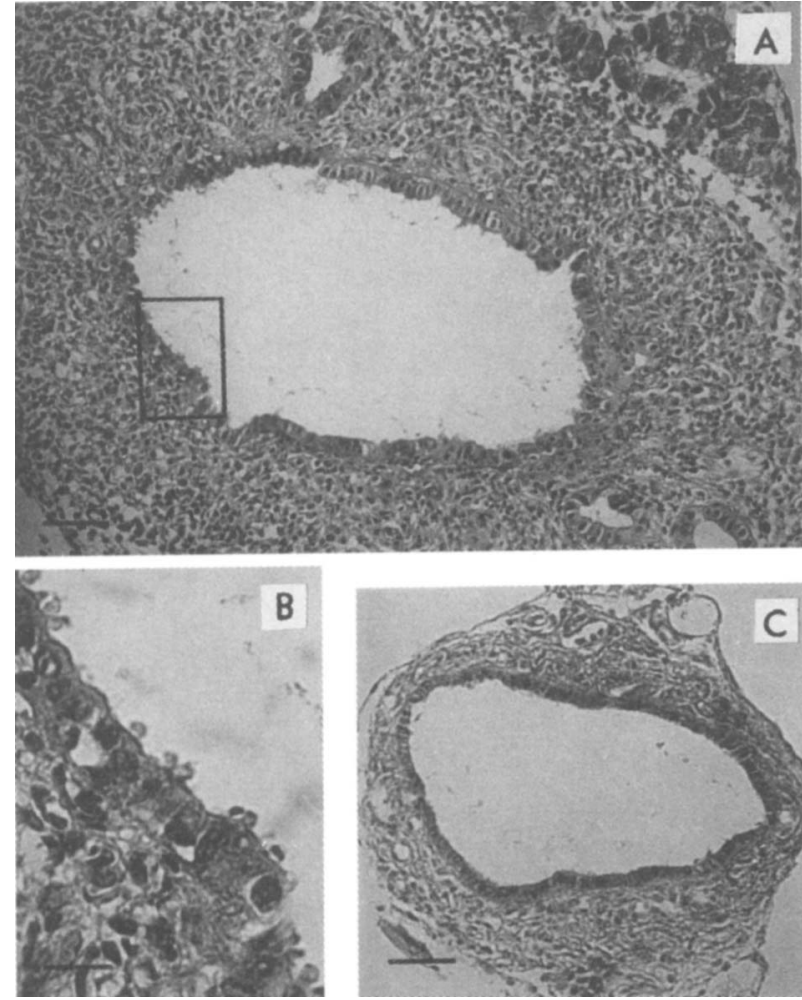

Fig. 2. (A) Photomicrograph of a common bile duct section in an adult immunocompetent BALB/c mouse infected with $10^{6} \mathrm{C}$. parvum by direct gall bladder inoculation. The thickness of the wall and the lumen diameter are increased. The epithelium is irregular, with massive cellular infiltration of the lamina propria. (B) High magnification of area in rectangle in A, showing intracellular parasitic stages. (C) Common bile duct section of an adult immunocompetent $\mathrm{BALB} / \mathrm{c}$ mouse inoculated with PBS. For A and C, bar $=5 \mu \mathrm{m}$ and for $\mathrm{C}$, bar $=25 \mu \mathrm{m}$.
Because the gall bladder frequently adhered to the adjacent hepatic lobe and its morphology appeared to be severely altered, histological sections and quantitative assessment of parasitic load were difficult to obtain. Subsequent studies were performed with histological sections of the common bile duct.

Infection of the common bile duct in adult mice was further characterised by the study of the kinetics of infection after inoculation of $10^{6}$ oocysts into the gall bladder. All mice survived and no clinical signs were observed in infected animals compared with controls. As shown in Table 1, the intensity of infection in the common bile duct was maximum on day 7 p.i. and spontaneous clearing of infection occurred in all animals by day 21 p.i. Macroscopic and histological inflammatory lesions similar to those described in experiment 1 were observed on days 7 and 14 p.i.

Table 1. Time-course of common bile duct infection scores in immunocompetent adult BALB/c mice after intra-gall bladder inoculation of $C$. parvum oocysts*

\begin{tabular}{ccc}
\hline & \multicolumn{2}{c}{ Common bile duct score } \\
\cline { 2 - 3 } Day p.i. & Mean score (SEM) & $\begin{array}{c}\text { Number of infected } \\
\text { animals (\%) }\end{array}$ \\
\hline 0 & 0 & 0 \\
7 & $1.80(0.37)$ & $5(100)$ \\
14 & $0.60(0.24)$ & $3(60)$ \\
21 & 0 & 0 \\
28 & 0 & 0 \\
35 & 0 & 0 \\
\hline
\end{tabular}

*At each time-point, one control mouse inoculated with PBS was killed and all were uninfected on histological study.

${ }^{\dagger}$ Five animals per group.

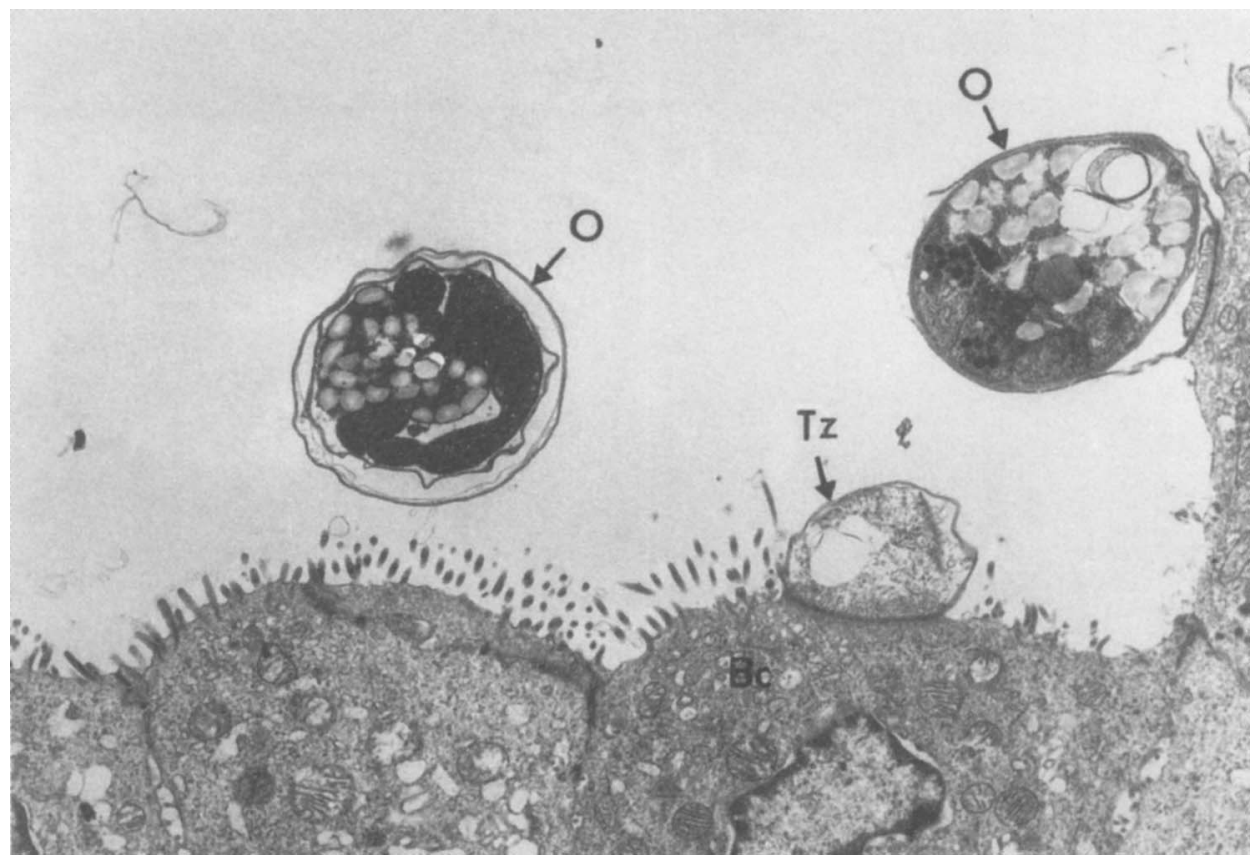

Fig. 3. Transmission electron micrograph of common bile duct epithelium from an adult immunocompetent BALB/c mouse infected with $10^{6} \mathrm{C}$. parvum by direct gall bladder inoculation: $\mathrm{Bc}$, biliary epithelial cell; $\mathrm{O}$, oocyst; $\mathrm{Tz}$, trophozoite. Magnification $\times 4800$. 
Histological studies on day 21 p.i. and later showed a normal epithelial structure and a marked diminution of inflammation in the lamina propria.

Serum IgG, IgA and IgM responses to $C$. parvum were detectable in all animals on day 14 p.i. and later (Fig. 4). On day 35 p.i., the bile collected from the gall bladder was tested for the presence of specific antibodies. C. parvum specific $\operatorname{IgG}$ and $\operatorname{IgA}$ were detected, while very low readings were found for IgM (Fig. 5).

To evaluate the possibility of strain differences in susceptibility to common bile duct infection, BALB/c and $\mathrm{C} 57 \mathrm{BL} / 6$ mice were infected in parallel and common bile duct, duodenum and ileum infection scores were evaluated on days $3,7,10$ and 14 p.i.

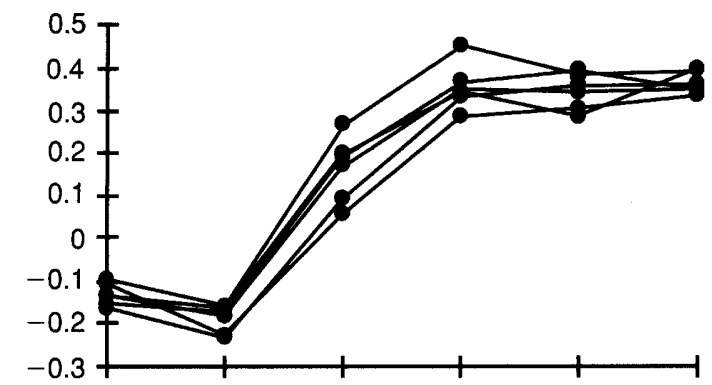

b
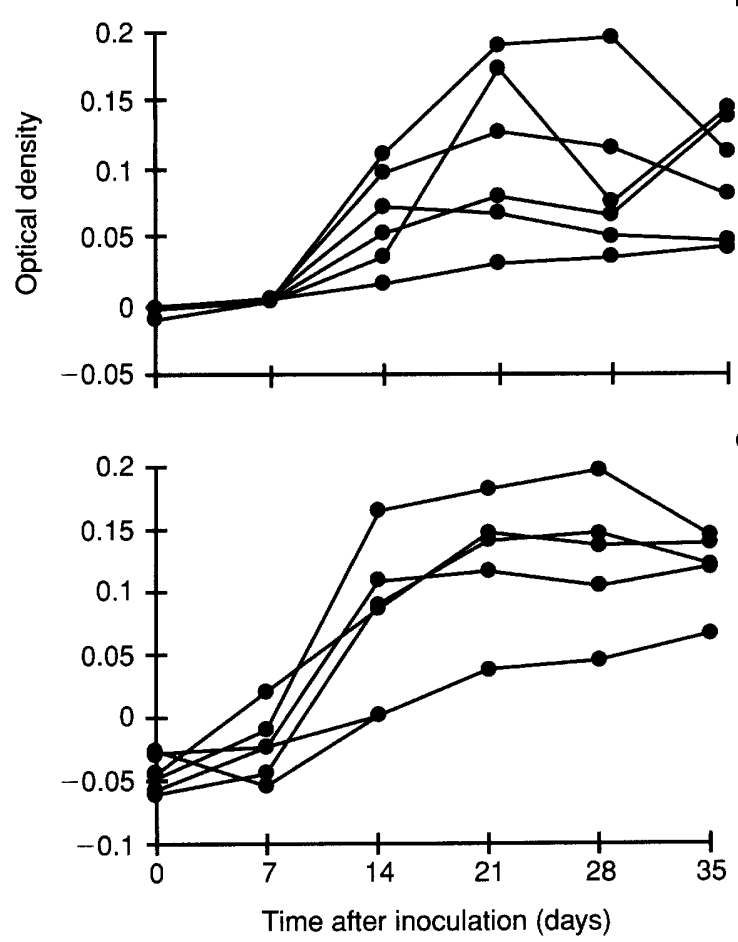

Fig. 4. Serum antibody response against $C$. parvum in adult $\mathrm{BALB} / \mathrm{c}$ mice with common bile duct $C$. parvum infection. Six mice were infected by injection of $10^{6}$ oocysts into the gall bladder and their sera sampled for determination of their anti-C. parvum antibody responses with an ELISA assay. (a) IgG response; (b) IgA response; (c) IgM response.

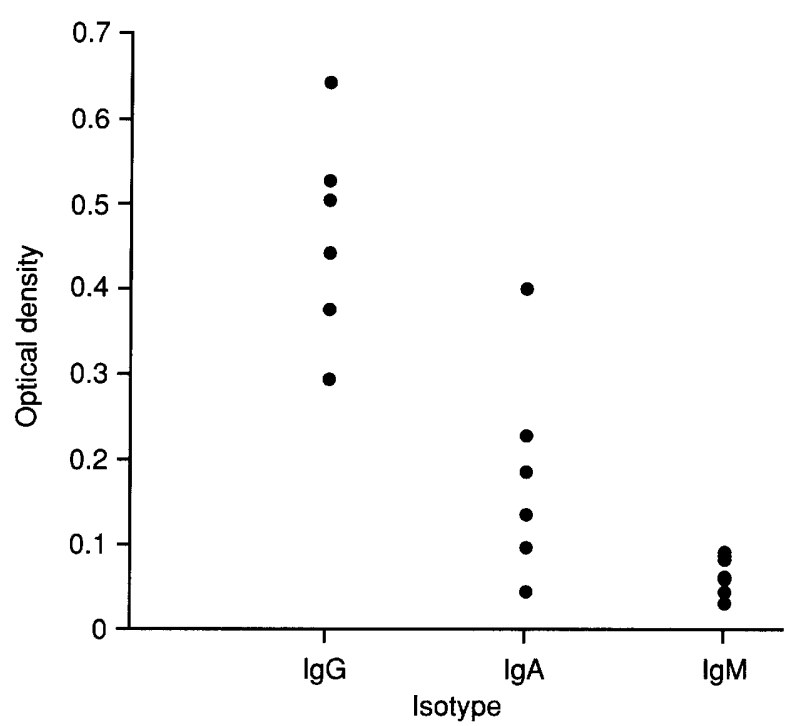

Fig. 5. Bile antibody response against $C$. parvum in adult BALB/c mice with common bile duct $C$. parvum infection. Six mice were infected by injection of $10^{6}$ oocysts into the gall bladder. On day 35 post-inoculation, bile was collected from the gall bladder and the anti- $C$. parvum $\mathrm{IgG}$, IgA and $\operatorname{IgM}$ responses were determined with an ELISA assay.

(experiment 3). No deaths or abnormal clinical signs were seen. As shown in Table 2, on days 3 and 7 p.i., animals of both strains had detectable parasites in common bile duct and gall bladder sections. On days 10 and 14 p.i., the infection scores as well as the percentages of infected animals decreased. Eradication of common bile duct infection was obtained in most animals on day 14 p.i. There was no difference in the intensity of common bile duct infection between $\mathrm{BALB} / \mathrm{c}$ and $\mathrm{C} 57 \mathrm{BL} / 6$ mice. Histological examination of duodenum and ileal sections did not show any parasites.

To assess how immunosuppression could modulate infection in this system, common bile duct, duodenum and ileum infection scores were measured on days 7 , 14 and 21 p.i. in BALB/c and C57BL/6 mice with or without dexamethasone treatment (experiment 4). The animals tolerated the procedure well and no deaths were observed during follow-up. For technical reasons, three C57BL/6 mice instead of four were available for study on day 7 p.i. As shown in Table 2, dexamethasone-treated mice of both $\mathrm{BALB} / \mathrm{c}$ and $\mathrm{C} 57 \mathrm{BL} / 6$ strains had significantly greater common bile duct infection scores than their immunocompetent counterparts on day 14 p.i. (2.75 SEM 0.25 versus 0.25 SEM 0.25 and 2.25 SEM 0.25 versus 0 respectively, $\mathrm{p}<0.05$, Mann-Whitney test). In contrast to immunocompetent adult mice, dexamethasone-treated adult mice were unable to clear the infection from their common bile duct, as demonstrated by the persistence of high infection scores on day 21 . The common bile duct scores in $\mathrm{BALB} / \mathrm{c}$ and $\mathrm{C} 57 \mathrm{BL} / 6$ dexamethasonetreated adult mice did not differ significantly. 
Table 2. Common bile duct and ileum infection (parasite density) scores in adult immunocompetent BALB/c and C57BL/6 mice with or without dexamethasone treatment

\begin{tabular}{|c|c|c|c|c|c|c|c|}
\hline \multirow[b]{2}{*}{ Mouse strain } & \multirow[b]{2}{*}{ Day p.i. } & \multicolumn{2}{|c|}{ Not treated by dexamethasone } & \multicolumn{4}{|c|}{ Treated by dexamethasone ${ }^{*}$} \\
\hline & & $\begin{array}{c}\text { Common bile duct } \\
\text { score: }{ }^{\dagger} \\
\text { mean } \pm \text { SEM (n) }\end{array}$ & $\begin{array}{c}\text { Number of } \\
\text { infected animals } \\
(\%)\end{array}$ & $\begin{array}{c}\text { Common bile duct } \\
\text { score: }^{\dagger} \\
\text { mean } \pm \text { SEM (n) }\end{array}$ & $\begin{array}{c}\text { Number of } \\
\text { infected animals } \\
(\%)\end{array}$ & $\begin{array}{l}\text { Ileum score: }{ }^{\dagger} \\
\text { mean } \pm \text { SEM } \\
(\mathrm{n})\end{array}$ & $\begin{array}{c}\text { Number of } \\
\text { infected animals } \\
(\%)\end{array}$ \\
\hline \multirow[t]{5}{*}{$\mathrm{BALB} / \mathrm{c}$} & 3 & $1.75 \underset{(4)}{ \pm} 0.25$ & $\begin{array}{c}4 \\
(100)\end{array}$ & ND & ND & ND & ND \\
\hline & 7 & $\begin{array}{c}1.5 \pm 0.50 \\
(4)\end{array}$ & $\begin{array}{c}4 \\
(100)\end{array}$ & $1.75 \underset{(4)}{ \pm} 0.48$ & $\begin{array}{c}4 \\
(100)\end{array}$ & $\begin{array}{c}0 \\
(4)\end{array}$ & 0 \\
\hline & 10 & $\begin{array}{c}1.25 \pm 0.48 \\
\text { (4) }\end{array}$ & $\begin{array}{c}3 \\
(75)\end{array}$ & ND & ND & ND & ND \\
\hline & 14 & $0.25 \pm 0.25$ & $\begin{array}{c}1 \\
(25)\end{array}$ & $2.75 \pm 0.25^{4}$ & $\begin{array}{c}4 \\
(100)\end{array}$ & $\begin{array}{c}0.75 \pm 0.25 \\
(4)\end{array}$ & $\begin{array}{c}3 \\
(75)\end{array}$ \\
\hline & 21 & ND & ND & $2.50 \pm 0.50$ & $\begin{array}{c}4 \\
(100)\end{array}$ & $2.25 \pm 0.48$ & $\begin{array}{c}4 \\
(100)\end{array}$ \\
\hline \multirow[t]{5}{*}{$\mathrm{C} 57 \mathrm{BL} / 6$} & 3 & $1.25 \pm 0.25$ & $\begin{array}{c}4 \\
(100)\end{array}$ & ND & ND & ND & ND \\
\hline & 7 & $\begin{array}{c}1.75 \pm 0.48 \\
\text { (4) }\end{array}$ & $\begin{array}{c}4 \\
(100)\end{array}$ & $2 \pm 0.58$ & $\begin{array}{c}3 \\
(100)\end{array}$ & $\begin{array}{c}0.67 \pm 0.3 \\
\text { (3) }\end{array}$ & $\begin{array}{c}2 \\
(66)\end{array}$ \\
\hline & 10 & $1 \pm 0.41$ & $\begin{array}{c}3 \\
(75)\end{array}$ & ND & ND & ND & ND \\
\hline & 14 & $\begin{array}{c}0 \\
(4)\end{array}$ & $\begin{array}{c}0 \\
(0)\end{array}$ & $\begin{array}{c}2.25 \pm 0.25^{\S} \\
(4)\end{array}$ & $\begin{array}{c}4 \\
(100)\end{array}$ & $2.30 \pm 0.33^{\|}$ & $\begin{array}{c}3 \\
(75)\end{array}$ \\
\hline & 21 & ND & ND & $2.25 \pm 0.25$ & $\begin{array}{c}4 \\
(100)\end{array}$ & $\begin{array}{c}3 \pm 0 \\
(4)\end{array}$ & $\begin{array}{c}4 \\
(100)\end{array}$ \\
\hline
\end{tabular}

ND, not done.

${ }^{*}$ Dexamethasone was given at a daily dose of $0.25 \mathrm{mg} / \mathrm{kg}$ /day from 7 days before oocyst challenge and continued throughout the experiment tSee Materials and methods for definition of infection scores.

Significantly different from immunocompetent BALB/c common bile duct score at day 14 (Mann-Whitney test, $\mathrm{p}<0.05$ ).

${ }^{\$}$ Significantly different from immunocompetent $\mathrm{C} 57 \mathrm{BL} / 6$ common bile duct score at day 14 (Mann-Whitney test, $\left.p<0.05\right)$.

Significantly different from immunosuppressed BALB/c ileum score at day 14 (Mann-Whitney test, $\mathrm{p}<0.05$ )

Dexamethasone-treated adult mice developed intestinal infection after the establishment of the biliary tract infection. Although no parasites were detected in duodenal sections, examination of ileal sections revealed numerous $C$. parvum organisms on days 14 and 21 p.i. (Table 2). Ileal infection tended to occur earlier in C57BL/6 dexamethasone-treated mice and the ileum infection score was significantly greater in $\mathrm{C} 57 \mathrm{BL} / 6$ mice than in $\mathrm{BALB} / \mathrm{c}$ on day 14 (2.30 SEM 0.33 versus 0.75 SEM $0.25, \mathrm{p}<0.05$ ).

Serum samples obtained from dexamethasone-treated mice (experiment 4) were tested for the presence of $C$. parvum specific antibodies in an ELISA as described previously but with an antibody to mouse immunoglobulin labelled with alkaline phosphatase as second antibody. No antibody response was detected (data not shown).

\section{Discussion}

Animal models of intestinal infection with C. parvum have been described in various neonatal or immunosuppressed hosts. In neonatal mice, piglets, lambs, calves and macaque monkeys, the establishment of the parasite is transient and probably related to the immunological incompetence of the immature immune system [1]. In immunosuppressed rodents, C. parvum intestinal infection is chronic and frequently complicated by biliary involvement [6-11]. Some of these animal models have well-characterised immune defi- ciencies, thus permitting the identification of immunological processes that may be critical in the control of C. parvum infection. There are few reports of attempts to study the immune response against $C$. parvum in an immunocompetent adult laboratory animal. Patent infections have been obtained in adult immunocompetent guinea-pigs with a Cryptosporidium isolate that was not $C$. parvum [13]. A recent study has suggested that adult immunocompetent mice may harbour latent intestinal $C$. parvum infection in the epithelial cells covering the Peyer's patches [14].

The present study provided morphological and serological evidence that adult immunocompetent mice inoculated with $C$. parvum oocysts by direct intra-gall bladder inoculation developed gall bladder and common bile duct $C$. parvum infections. The development of intracellular parasitic stages was demonstrated by haematoxylin-eosin staining and electron microscopy. Biliary tract infection could be monitored easily by histological study of common bile duct sections. Infected mice developed significant serum and bile $C$. parvum specific antibody levels compared with noninfected animals. While infection was demonstrated in the biliary tract of immunocompetent animals, no parasite was found in the duodenum or the ileum. The anatomical conditions and the stasis in the gall bladder may provide favourable conditions for the establishment of infection in the biliary tract. Bile components have an enhancing effect on $C$. parvum excystation and may also stimulate invasion and intracellular development of parasites in cell culture $[15,16]$. 
A strong inflammatory response was observed in common bile duct histological sections of infected animals. No common bile duct inflammation was found in controls inoculated with PBS, heat-inactivated oocysts or a filtrate of an oocyst suspension, suggesting that the inflammatory reaction observed in infected animals is related to the interaction of $C$. parvum development with the biliary epithelium.

Dexamethasone treatment was associated with the inability of the host to eradicate the infection from the biliary tract as has been shown for the intestine in other studies [17]. In dexamethasone-treated mice, the ileum was heavily infected while the duodenum, which is directly adjacent to the biliary tract, was not. This strongly suggests that favourable conditions in the ileum contribute to the development of the parasite. These hypothetical factors (e.g., specific receptors, biochemical conditions) remain to be determined. The development of intestinal infection following the establishment of biliary tract infection is consistent with the hypothesis that intestinal infection in man may be maintained by a biliary reservoir. It is of interest that ileal infection was more severe in $\mathrm{C} 57 \mathrm{BL} / 6$ than in $\mathrm{BALB} / \mathrm{c}$ mice, suggesting a greater sensitivity of $\mathrm{C} 57 \mathrm{BL} / 6$ mice to $C$. parvum infection, a finding that has been reported by others following intestinal challenge [17].

The present study shows that adult immunocompetent mice develop a self-resolving common bile duct infection following injection of oocysts into the gall bladder, with severe inflammatory lesions of the biliary tract. Monitoring of infection can be done by studying common bile duct histological sections. Clearance of the parasite from the common bile duct was obtained by day 21 p.i., suggesting that this model could be of interest in the study of the immunologicals processes involved in the control of biliary cryptosporidiosis.

This work was supported by a Sidaction grant (number 7907) from the Fondation pour la Recherche Médicale. We thank O. Domarle for help in photography, Honorine Ward and Maura Kelley for help in standardising the ELISA and G. Mikant and C. Legrand for maintenance and care of the research animals.

\section{References}

1. Current WL, Garcia LS. Cryptosporidiosis. Clin Microbiol Rev 1991; 4: 325-358.

2. Benhamou Y, Caumes E, Gerosa Y et al. AIDS-related cholangiopathy. Critical analysis of a prospective series of 26 patients. Dig Dis Sci 1993; 38: 1113-1118.

3. Forbes A, Blanshard C, Gazzard B. Natural history of AIDS related sclerosing cholangitis: a study of 20 cases. Gut 1993; 34: 116-121.

4. Cello JP. Acquired immunodeficiency syndrome cholangiopathy: spectrum of disease. Am J Med 1989; 86: 539-546.

5. Vakil NB, Schwartz SM, Buggy BP et al. Biliary cryptosporidiosis in HIV-infected people after the waterborne outbreak of cryptosporidiosis in Milwaukee. $N$ Engl J Med 1996; 334: 19-23.

6. Ungar BLP, Burris JA, Quinn CA, Finkelman FD. New mouse models for chronic Cryptosporidium infection in immunodeficient hosts. Infect Immun 1990; 58: 961-969.

7. Mead JR, Arrowood MJ, Sidwell RW, Healey MC. Chronic Cryptosporidium parvum infections in congenitally immunodeficient SCID and nude mice. $J$ Infect Dis 1991; 163: 1297-1304.

8. Brasseur P, Lemeteil D, Ballet J-J. Curative and preventive anticryptosporidium activities of sinefungin in an immunosuppressed adult rat model. Antimicrob Agents Chemother 1993; 37: $889-892$.

9. Mead JR, Ilksoy N, You X et al. Infection dynamics and clinical features of cryptosporidiosis in SCID mice. Infect Immun 1994; 62: 1691-1695.

10. Regh JE. A comparison of anticryptosporidial activity of halofuginone with that of other aminoglycosides and azithromycin in immunosuppressed rats. $J$ Antimicrob Chemother 1994; 170: 934-938.

11. Tzipori ST, Rand W, Theodos C. Evaluation of a two-phase scid mouse model preconditioned with anti-interferon-gamma monoclonal antibody for drug testing against Cryptosporidium parvum. J Infect Dis 1995; 172: 1160-1164.

12. Ungar BLP, Soave R, Fayer R, Nash TE. Enzyme immunoassay of immunoglobulin $\mathrm{M}$ and $\mathrm{G}$ antibodies to Cryptosporidium in immunocompetent and immunocompromised persons. $J$ Infect Dis 1986; 153: $570-578$.

13. Chrisp CE, Reid WC, Rush HG, Suckow MA, Bush A, Thomann MJ. Cryptosporidiosis in guinea pigs: an animal model. Infect Immun 1990; 58: 674-679.

14. Johansen GA, Sterling CR. Detection of a prolonged $C$. parvum infection in immunocompetent adult $\mathrm{C} 57 \mathrm{BL} / 6 \mathrm{mice}$. $J$ Eukaryot Microbiol 1994; 41: 45S.

15. Campbell AT, Robertson LJ, Smith HV. Viability of Cryptosporidium parvum oocysts: correlation of in vitro excystation with inclusion of fluorogenic vital dyes. Appl Environ Microbiol 1992; 58: Suppl: 3488-3493.

16. Gut J, Petersen C, Nelson R, Leech J. Cryptosporidium parvum: in vitro cultivation in Madin-Darby canine kidney cells. J Protozool 1991; 38: 72S-73S.

17. Rasmussen KR, Healey MC. Experimental Cryptosporidium parvum infections in immunosuppressed adult mice. Infect Immun 1992; 60: 1648-1652. 